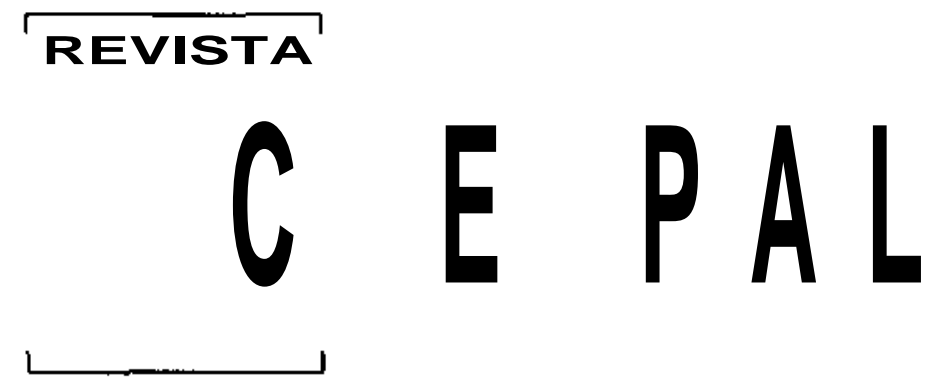

NUMERO 65

AGOSTO 1998

SANTIAGO DE CHILE

ÓSCAR ALTIMIR

Director

EUGENIO LAHERA

Secretario Técnico

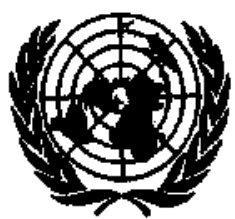

NACIONES UNIDAS 
Distribución del ingreso, pobreza y gasto social en América Latina José Antonio Ocampo

Gasto militar y el desarrollo en América Latina

Eugenio Lahera y Marcelo Ortúzar

Crecimiento, justicia distributiva y política social

Andrés Solimano

Equidad, inversión extranjera y competitividad internacional

Adolfo Figueroa

Tensiones en el ajuste estructural en América Latina: asignación vs. distribución

Daniel M. Schydlowsky

Competitividad y regulaciones laborales

Luis Beccaria y Pedro Galín

Familias latinoamericanas: convergencias y divergencias de modelos y políticas

Irma Amagada

Los acuerdos de libre comercio y el trabajo de las mujeres:

el caso de Chile

Alicia Frohmann y Pilar Romaguera

Evolución macroeconómica del Paraguay 1989-1997:

burbuja de consumo y crisis financiera

119 L.-

Siéphane Straub

Estrategias de las empresas mexicanas en sus procesos de internacionalización

Alejandra Salas-Porras

La regulación de la prestación privada de servicios de agua potable y alcantarillado

Terence R. Lee y Andrei S. Jouravlev

Promoción de la calidad para mejorar la competitividad $169 v^{\prime}$ Hessel Schuurman 


\section{Tensiones en el ajuste estructural en América Latina: asignación vs. distribución}

Daniel M. Schydlowsky

Profesar de Economía, American University, Washington, D.C.
En la historia económica de América Latina, crecía la población y exigía nuevos empleos. Para crear nuevos puestos de trabajo era necesaria la industrialización; para industrializar había que cubrir un diferencial de productividad. Dos opciones eran factibles: i) preservar la eficiencia en la asignación, generando una importante redistribución regresiva del ingreso; y ii) perder eficiencia en la asignación manteniendo sin grandes cambios la distribución del ingreso; al escoger ésta última, los gobiernos introdujeron distorsiones permanentes en el mercado cambiario. La industrialización basada en la sustitución de importaciones llevó al estancamiento. La creciente presión sobre el mercado del trabajo pudo haber hecho descender abruptamente los salarios; en cambio, surgió el mercado informal que, gracias a su estructura competitiva monopolística, segmentó los mercados de bienes, asegurando una distribución mínima aceptable del ingreso. No hubo políticas públicas al respecto. El propio mercado generó una red de seguridad natural. Sin embargo, se sacrificó la eficiencia de asignación, introduciéndose distorsiones permanentes en el mercado del trabajo. El desarrollo financiero fue incapaz de responder a los nuevos requerimientos y la segmentación del mercado de capitales fortaleció aún más las distorsiones en el sistema de precios. La polf́tica de ajuste estructural eliminó algunas de las distorsiones de precio en los mercados cambiario y de crédito. La redistribución de la propiedad a través de los años modificó los efectos redistributivos de las variaciones en los precios relativos. Sin embargo, el ajuste estructural trajo consigo una entrada de capitales que llevó a una sobrevaluación considerable del tipo de cambio, mientras la división en el mercado de trabajo persistía y afectaba a más trabajadores que antes. A su vez, la liberalización del comercio se traducía en la contabilidad de los bancos como garantías debilitadas y deudas incobrables de empresas que habían quedado desprotegidas por la baja de aranceles y el tipo de cambio sobrevaluado. El sistema de precios de mercado en este caso no entrega - ni con mucho- las señales correctas para una buena asignación de los recursos. La necesidad de ingresos sigue impulsando el crecimiento del sector informal, mientras que el capital interno y los trabajadores desconfían de la inversión externa, sin saber si es amiga o enemiga. 
I

\section{Introducción}

Las tensiones entre asignación y distribución en el contexto del crecimiento económico tradicionalmente han inspirado dos líneas principales de investigación. Por una parte, está el conjunto de problemas que se resumen en la curva de Kuznets: ¿es inevitable un aumento de la inequidad en la primera fase del crecimiento o puede ser amortiguado, o eliminado por completo, con una adecuada combinación de políticas?

La segunda línea de investigación se ha centrado en las tasas diferenciales de ahorro: si los ricos ahorran más que los pobres, entonces la inequidad producirá mayor crecimiento que la equidad. El desafío de política es entonces encontrar mecanismos de intervención que sean capaces de igualar las tasas de ahorro o, si ello no es posible, generar suficiente ahorro público para contrarrestar cualquier efecto negativo de una mayor equidad.

Sin embargo, aún en un contexto estático, existe un conflicto latente entre asignación y distribución. Es sabido que el óptimo de Pareto no garantiza una distribución aceptable. Al mismo tiempo, los intentos por corregir la distribución por la vía de la intervención pública casi inevitablemente distorsionan la eficiencia en la asignación de recursos.

Así pues, que existan tensiones entre distribución y asignación durante el ajuste estructural de una economía es algo que debe esperarse por anticipado.

En el contexto de América Latina, se ha destacado la importancia de la distribución desde variadas perspectivas. Primero, hay muchos trabajos de investigación respecto de la desigualdad del ingreso en el hemisferio y concluyen, en general, que en América Latina, como un todo, esa desigualdad ha sido mucho mayor que en otras regiones en desarrollo, particularmente en Asia. Segundo, se ha señalado la función distributiva como fuerza motriz en la creación de las redes tradicionales de segunidad social: mecanismos de fijación de salarios del sector público, leyes de prestaciones sociales, protección sindical, leyes de seguro social, etc. Tercero, se han identificado los aspectos distributivos como parte integral de los procesos inflacionarios de América Latina. Mientras algunos autores sostienen que muchas inflaciones latinoamericanas serían resultado de disputas distributivas entre distintos sectores organizados de la sociedad, existe un amplio consenso de que la indización, tanto explícita como implícita, se ha debido al propósito de proteger las participaciones en la distribución y los ingresos reales del efecto erosivo de la inflación.

El objetivo de este trabajo es centrar la atención en un conjunto de temas bastante distintos. Busca observar los efectos de los problemas distributivos en el patrón de especialización sectorial, ya sea explícitamente, como resultado de la política pública, o implícitamente a través de la función del sistema de precios.

Empezaremos por explorar cómo las preocupaciones distributivas fundamentales delinearon la política de industrialización y de esta forma determinaron el curso de la industrialización sustitutiva de importaciones en América Latina. En seguida examinaremos cómo los intereses redistributivos se reflejan espontáneamente en el sistema de precios durante el estancamiento, lo que determina las condiciones iniciales de la fase de ajuste estructural. Luego, analizaremos esta última fase para determinar en qué grado las tensiones iniciales persisten o han sido superadas. Se exploran asimismo otras fuentes de tensión distributiva. En las conclusiones se da una visión global de la secuencia descrita y de los argumentos utilizados.

\section{II}

\section{La fase de industrialización activa}

Es un lugar común que los distintos países de América Latina son diferentes. Pese a todas las diferencias,

:." Una versión anterior do este trabajo se presentó al Southern Economics Associatíon Meetings, en Washington D.C. sin embargo, hay un padrón común en el desarrollo económico latinoamericano que es útil resumir en algunas características. Llamaremos a esta realidad estilizada "Latinia", el "país típico" de América Latina. 
Antes de la industrialización activa (recién terminada la segunda guerra mundial), las principales actividades económicas de Latinia eran la agricultura y la minería, ambas mayoritariamente de exportación, aunque parte de la agricultura se destinaba a satisfacer la demanda interna de alimentos, los productos industriales eran en su mayoría importados y los tipos de cambio se fijaban a un nivel que permitía la competencia de las exportaciones tradicionales en los mercados mundiales mientras los aranceles de importación tenían por finalidad principal allegar recursos al erario nacional. La producción de las exportaciones se concentraba en unidades relativamente grandes de propiedad de pocas personas, en su mayor parte integrantes de la élite del país, la que también se turnaba para gobernar. Algunas actividades de exportación eran de propiedad de inversionistas extranjeros.

La industrialización se impulsó a un mismo tiempo desde abajo y desde arriba. Desde abajo, vino la presión demográfica, alimentada principalmente por los grandes avances de la salud pública. Una fuerza trabajadora en rápido crecimiento no encontraba cabida en la agricultura ni en la minería. Las limitaciones naturales en la capacidad del túnel de la mina y el decreciente producto marginal del trabajo agrícola establecían límites estrictos a la cantidad de personas adicionales que podían absorber los sectores tradicionales.

En la industria, en cambio, la capacidad de generar empleo sólo se limitaba por factores humanos. Todos podrían tener empleo si se instalaba un número suficiente de fábricas. Por ello, una fuerza de trabajo creciente en demanda de trabajo constituía un sólido argumento en favor de la industrialización para las élites dirigentes, que ciertamente deseaban evitar la convulsión social.

De arriba vino el concepto de la modernidad. Las élites se dieron cuenta de que un país moderno era virtual sinónimo de un país industrial. Para que sus países fueran modernos, entonces, requerían la industrialización. Como las presiones de abajo y de arriba coincidían, no había razón para que el gobierno de Latinia se resistiera a la industrialización como estrategia de desarrollo.

Sin embargo, desarrollar la industria en Latinia significaba moverse en una curva de costos de ventajas comparativas a actividades de costo más elevado. Los procesos industriales eran de mayor costo que la agricultura y la minería tradicionales por una variedad de motivos: a) eran actividades nuevas, por lo que, al menos durante un período de aprendizaje inicial, ten- drían costos más elevados que aquellas en las que el país tenía experiencia; b) los procesos industriales tienen economías de escala, y los mercados de Latinia eran pequeños; nuevamente, entonces, los costos serían inicialmente elevados; c) la nueva industria tendría que apoyarse en una industria de insumos que no existía, lo que hacía más cara la producción local, consecuencia de la naturaleza sistémica de la producción industrial; d) la infraestructura no estaba orientada a la producción industrial, sino a las exportaciones agrícolas y mineras; e) los consumidores preferían claramente los productos importados, cuya calidad se presumía mejor, lo que imponía un castigo artificial a los precios de la producción local. Además, la producción industrial estaría sujeta a normas laborales avanzadas, con especificación de horas máximas de trabajo, salarios mínimos, beneficios no salariales, seguridad social, derechos de negociación colectiva de los trabajadores, sindicatos, etc., la mayor parte de las cuales no regían para la agricultura ni la pequeña y mediana minería.

Todas estas características hicieron ver la necesidad de formular políticas para hacer competitiva esta nueva producción industrial. ${ }^{1}$

El problema que enfrentaban los gobernantes se ilustra en el gráfico 1. La curva SS es la oferta agregada que muestra la diferencia de costos entre los sectores primarios de la agricultura y la minería y los nuevos sectores industriales. $\mathrm{R}_{\mathrm{o}}$ es el nivel del tipo de cambio, medido en pesos por dólar, en una posición

GRÁFICO 1

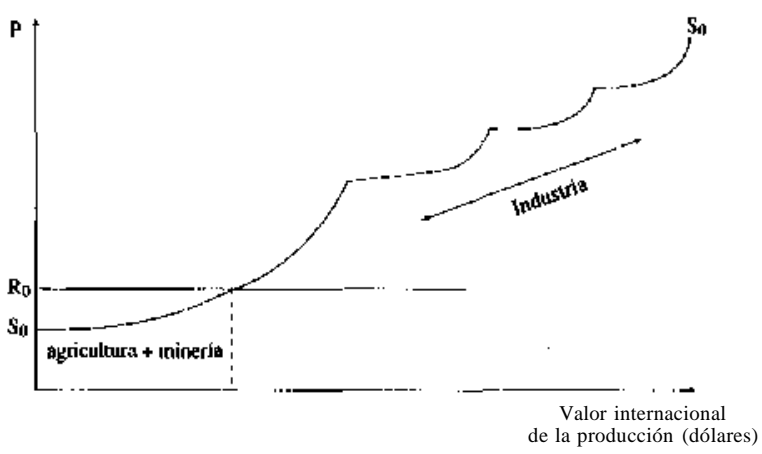

1 Nótese que la idea de que proteger a la industria naciente es en verdad una solución subóptima frente a la de perfeccionar el mercado de capitales para que el sector privado pueda financiar la cobertura de sus propios riesgos resultaba demasiado sofisticada para que los gobiernos de la época pudieran siquiera considerarla. 
que permite la exportación de la producción tradicional, pero es demasiado bajo para que la nueva producción industrial compita con las importaciones. Por consiguiente, hay producción sólo en la parte de la curva de oferta que corresponde a los sectores primarios. El problema de política consiste en hacer competitiva la actividad industrial.

En estas circunstancias, el gobierno de Latinia tiene tres opciones: i) la devaluación general, ii) una devaluación selectiva, iii) la devaluación compensada. Exploremos cada una con la ayuda del gráfico 2.

i) Devaluación general: En esta opción, el tipo de cambio $R_{o}$ se de valúa a $R_{r}$ a una mayor cantidad de pesos por dólar. Abstrayendo cualquier efecto de la devaluación sobre el alza de costos, puede verse en el gráfico 2 que con $\mathrm{R}_{\text {( }}$ una cierta cantidad de actividades industriales pasa a ser competitiva. Más aún, hay una expansión de la producción primaria en la medida que los productores de estos sectores se mueven hacia arriba en la curva de costos. En términos marginales, la productividad de los sectores primario e industrial se igualan; por lo tanto, hay eficiencia en la asignación de recursos. Además, sin embargo, hay una redistribución masiva del ingreso, en la medida en que los productores intramarginales de bienes primarios obtienen un ingreso significativamente más alto por la cantidad que producían originalmente. Este ingreso adicional proviene, directamente, de los compradores de alimentos del mercado locál e, indirectamente, del tipo de cambio más elevado, que provoca un alza de precio de los bienes importados para todos los consumidores. En consecuencia, con una devaluación general, los dueños de propiedades mineras y empresas agrícolas obtienen una transferencia considerable de ingresos desde todos los consumidores.

ii) Devaluación selectiva: Esta opción consiste en aumentar sólo el tipo de cambio para productos de importación que compiten con los que se van a producir internamente. Con esta solución, la producción local se hace competitiva con las importaciones por la vía de implantar aranceles de importación, que producen el efecto de devaluar el tipo de cambio sólo para los productos que se busca proteger. En términos del gráfico 2, el tipo de cambio general se mantiene en $\mathrm{R}_{\mathrm{Q}}$, y se implantan aranceles de importación para los productos industriales uno y dos para cubrir las diferencias de costos de esos productos específicos. Ahora no hay expansión de la producción del sector primario; como resultado, ya no hay igualdad de costos marginales entre los sectores primario e industrial, lo que significa una producción ineficiente. Sin embargo, hay sólo un mínimo efecto en la distribución del ingreso porque en este caso, los productores originales de la minería y la agricultura no reciben ninguna utilidad imprevista. La única redistribución ocurre entre compradores de los bienes protegidos y los nuevos productores de los mismos bienes. Esto significa principalmente que los consumidores de ingresos medios pagan precios más altos por bienes producidos por trabajadores de clase media y baja y capitalistas de altos ingresos. $^{2}$

iii) Devaluación compensada: ${ }^{3}$ En este caso, el tipo de cambio se devalúa como en una devaluación general, de $\mathrm{R}_{\mathrm{o}}$ a $\mathrm{R}$,; sin embargo, los aranceles de importación se reducen en la misma magnitud y se aplica tributación a las utilidades imprevistas de los exportadores primarios. En su versión simple, se aplica un impuesto a las exportaciones tradicionales cuya tasa busca mantener el tipo de cambio neto para los exportadores tradicionales en $\mathrm{R}_{\mathrm{Q}}$. En otra variante, se aplica un impuesto Ricardiano sobre la propiedad, diseñado para neutralizar las utilidades imprevistas sólo de la producción preexistente. En ambos casos, los efectos redistributivos se mantienen al mínimo, en tanto que se consigue eficiencia en la asignación con el impuesto a la propiedad y no con un impuesto a la exportación. Un elemento final de este paquete es un mecanismo de devolución a los consumidores del costo adicional de compra de bienes tradicionales que resulta de la devaluación y que no puede ser compensado por

GRÁFICO 2

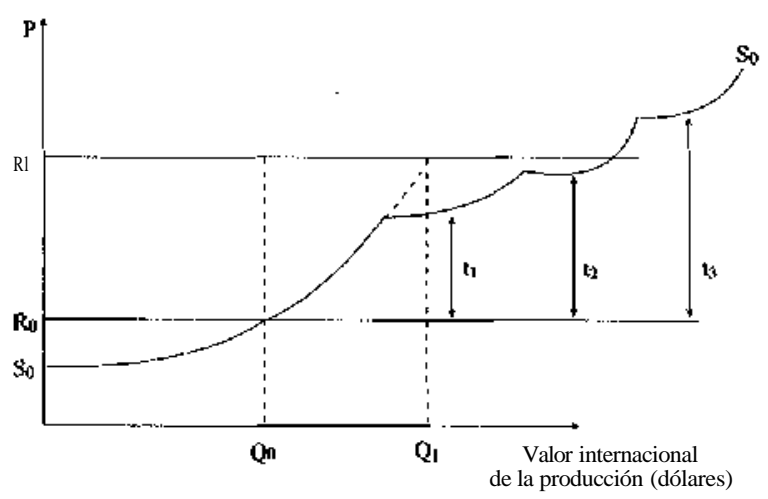

2 Los consumidores de bajos ingresos se ven afectados también por los precios más altos, pero en menor escala, ya que proporcíonalmente consumen menos de estos tipos de productos.

3 Propuesta inicialmente por Marcelo Diamand, de Argentina, en CARTTA (1966), propuesta independientemente por Schidlowsky (1967), adaptada posteriormente con algunas modificaciones al pensamiento predominante por Balassa (véase Balassa y otros, 1982). 
una reducción de aranceles o un impuesto a las exportaciones. Se concluye que la devaluación compensada es mucho más compleja en su diseño y administración que las otras dos opciones.

Visto desde la perspectiva de cualquier gobierno de Latinia en ese tiempo, la opción ii) era la obvia. La solución iii) no estaba siquiera incluida dentro del conjunto de opciones por ser demasiado compleja en diseño, administración y ejecución. La alternativa i) pudo haber sido factible. Sin embargo, hasta un gobierno de élite en Latinia lo habría pensado dos veces antes de impulsar una medida que condujera tan evidentemente a la concentración del ingreso, para qué decir de los gobiernos con mayor raigambre en la clase trabajadora, como el de Perón en la Argentina, y Vargas en el Brasil. ${ }^{4}$ Uno tras otro, los países del hemisferio implantaron la lógica estilizada de Latinia: subir los aranceles para hacer competitiva la nueva producción con las importaciones.

Una vez que la política se estableció, fueron apareciendo todas las consecuencias conocidas de la industrialización sustitutiva de importaciones:

i) La aversión a las exportaciones circunscribió a la nueva industria a su mercado interno;

ii) La ilusión de ineficiencia hizo que sectores que competían con las importaciones parecieran más ineficientes de lo que realmente eran; ${ }^{5}$ iii) Fue muy débil la promoción de las exportaciones, con la excepción de Brasil y Colombia, en parte debido a la ilusión de ineficiencia; en consecuencia, para ahorrar divisas se requería mayor sustitución de importaciones con aranceles más altos;

iv) Aumentó la vulnerabilidad a las fluctuaciones de balance de pagos en la medida en que las importaciones se fueron haciendo más indispensables.

v) El ciclo de la actividad económica estaba determinado por la disponibilidad de divisas.

vi) Se contrataba endeudamiento para aumentar la disponibilidad de divisas; sin embargo, a falta de cambios estructurales en los precios relativos y en la orientación de la producción al mercado, sólo se conseguía así ocultar los síntomas; había expansión cuando las divisas prestadas se utilizaban para pagar importaciones, pero luego sobrevenía la crisis, y ahora más grande, por la necesidad de servir la deuda.

La estructura de la producción en la economía tradicional y las diferencias de ventajas comparativas entre la producción tradicional y las actividades industriales fijaron una política básica. La opción de política se inspiraba en el anhelo de minimizar las consecuencias distributivas. El efecto fue una política comercial que al final condujo al estancamiento, en lo que se ha conocido como "la década perdida" de 1980.

\section{III}

\section{La fase del estancamiento}

El crecimiento económico se detuvo, pero no así el demográfico. Nuevos trabajadores ingresaban al mercado laboral y aumentaba cada vez más su dificultad para encontrar trabajo. Incapaces de encontrar empleo remunerado, y, a falta de otro derrotero, se convertían en trabajadores por cuenta propia. En esencia, migraron del mercado del trabajo al mercado de bienes. Comenzaron por el comercio ambulante y competían con el comercio establecido diferenciando el producto: ofrecían distintos lugares de venta (semáforos, ventas a domicilio), diferente envoltorio (sin envoltorio para que se viera la mercancía) y hasta diferentes formas de venta (posibilidad de regateo en vez de precio fijo).

4 Pedro Beltrán, Primer Ministro del segundo gobierno de Prado en Perú (1956-1962) promulgó la ley que aumentaba sistemáticamente la protección para estimular la industrialización.

5 Véanse Diamand (1973) y Schydlowsky (1972).
La estructura del mercado de este sector de la economía era de competencia monopolística, con sus dos características: el precio es igual al costo medio y existe capacidad instalada ociosa (véase Chamberlain, 1933). En este mercado informal, el costo total es igual al costo de materiales más el costo de la vida. Más aún, y como el costo de vida es un costo fijo que se prorratea entre el número de unidades vendidas, se genera la clásica curva de costos decrecientes, en que el costo marginal es inferior al costo medio. A su vez, la capacidad instalada ociosa asume la forma de subempleo de la fuerza laboral.

Como la población sigue creciendo, cada vez más individuos se incorporan al sector informal. Ocurren entonces tres reacciones: i) hay innovación en la informalización de nuevos sectores, nuevas áreas geográficas, nuevos productos (v.g. se reparan silenciadores en 
la vía pública, los productores informales de ropa que venden sus productos de manera informal); ii) aumenta la segmentación de los sectores informales existentes, bajando las participaciones individuales de mercado, de la manera prevista por Chamberlain, iii) hay un ajuste a la baja de la expectativa de costo de vida, acomodándose a las difíciles circunstancias de mercado que enfrentan los participantes.

A consecuencia del efecto conjunto de estos mecanismos de ajuste, crece el sector de competencia monopolística en la economía, cunde el subempleo, se aparta cada vez más el salario de mercado del costo marginal del trabajo y se asienta con más fuerza la situación de incumplimiento de las condiciones de Pareto en la economía.

El desarrollo de un sector informal que opera con una estructura de mercado de competencia monopolística es una adaptación natural frente a las necesidades de distribución. En un mercado competitivo, el ingreso de los trabajadores caería abruptamente. La legislación no permite que esto suceda en el sector formal. El incumplimiento de las reglas o su evasión por medio de la informalización podría llevar a tal descenso de los ingresos. En cambio, la competencia monopolística distribuye el ingreso disponible. Al mismo tiempo, el sector informal transfiere parte del ingreso desde el sector formal mediante la diferenciación de productos e incluso contribuye a liberalizar las restricciones cambiadas de la macroeconomía al preferir un conjunto de productos menos exigentes de divisas extranjeras. Es así como las exigencias distributivas tienen un efecto crítico sobre la composición de la producción y la selección de tecnología. Pero esto ocurre de manera espontánea, por el juego de las fuerzas del mercado. En esta evolución, el sistema de precios se ha distorsionado sin remedio, estableciéndose una fuerte barrera entre los salarios del mercado y el costo marginal del trabajo.

La evolución de) mercado financiero interactúa con esta modificación de la estructura productiva de la economía. Durante la fase preindustrial, la concesión de créditos es una operación muy personalizada. En esta etapa los banqueros conocen personalmente a la mayoría de sus clientes o hay incluso relaciones de familia con ellos. Prestar y pedir prestado es una actividad que se realiza dentro de una pequeña élite en que lo más importante es la reputación. Además, la operación de crédito suele ser una transacción comercial sencilla, generalmente para el comercio de importación o exportación.

Durante el período de industrialización activa, la naturaleza del crédito cambia. El otorgamiento de cré- ditos se despersonaliza, a medida que los bancos crecen y contratan funcionarios de crédito cuya función de pérdida es asimétrica. Mientras el banquero arriesga su propio dinero, el funcionario de crédito arriesga dinero ajeno. Un mal préstamo provocará su despido, pero el no conceder un buen crédito no se notará. De esta forma, el crédito se extiende durante esta etapa con una mayor aversión al riesgo. Por otro lado, los deudores ya no conocen a los prestamistas. No fueron a los mismos colegios, son demasiado numerosos como para tener relaciones familiares o para que sus reputaciones sean de conocimiento general. Más aún, el tipo de proyecto para el que se presta dinero es de mucho más largo plazo y más complicado, por ejemplo, para producción industrial. En consecuencia, las garantías surgen como elemento esencial del crédito. Sin garantías no hay créditos. Esto introduce una clara separación entre aquellos individuos que tienen activos que ofrecer en prenda y los que no los tienen.

Cuando sobreviene el estancamiento y aumenta la informalización de la economía, hay disponibilidad de crédito principalmente para el sector formal. Los informales no tienen garantías, las empresas formales, sí. No obstante, el estancamiento afecta la calidad de las garantías de las empresas formales. Primero, sus corrientes de fondos dejan de crecer como producto del estancamiento. Segundo, sus corrientes de fondos a menudo se reducen a consecuencia de las incursiones del sector informal en los mercados formales. La caída de las corrientes de fondos de los deudores se traduce inicialmente en un deterioro de las garantías y, de ahí, en un número creciente de deudas incobrables. La primera reacción de los bancos es repactar los créditos a la espera de que la situación mejore. Pero, como el estancamiento persiste, las deudas incobrables no reconocidas llegan a representar proporción importante de la cartera de préstamos, lo que pone en aprietos al sistema bancario.

Hay un mecanismo de propagación del crédito (layering) por el cual éste puede transferirse del sector formal al informal, usando como intermediarias a empresas formales proveedoras de los vendedores informales. Sin embargo, este mecanismo es de aplicación restringida. Por un lado, una parte importante del sector informal no tiene un vínculo estable con empresas específicas del sector formal. Por otro lado, la mayoría de los vendedores informales no tienen garantías que ofrecer, pueden estar hoy aquí y mañana no, prefieren negociar al contado y constituyen un riesgo significativo para las empresas proveedoras. Para que este 
sistema adquiera real impulso es preciso modificar las bases del crédito. Más que prestar con la seguridad de una garantía, debe prestarse (y pagarse) con el incentivo de acceso a un crédito mayor en la medida que se acumula un buen historial de cumplimiento. En otras palabras, la función de crédito debe evolucionar de la garantía hacia el incentivo. Por cierto, esto ha ocurrido, aunque toma tiempo en difundirse a todo el sistema económico. ${ }^{6}$

La evolución del mercado de capitales descrita tiene dos impactos macroeconómicos de importancia:

i) El acceso al crédito en distintas cantidades y a distintos precios en el sector formal e informal refuerza un dualismo tecnológico que no depende de ninguna legislación sobre el mercado de trabajo. Como resultado, hay dos niveles de ingreso y estructuras de decisión distintos. ${ }^{7}$ La distribución del crédito contribuye así a consolidar una distorsión significativa en el sistema de precios.

ii) El deterioro de la cartera del sistema bancario trae consigo un aumento de los costos de operación que no se refleja completamente en la contabilidad de los bancos. Consiguientemente, el costo real del crédito sube en la economía. Esto sucede conjuntamente con un aumento del riesgo según país percibido por los inversionistas extranjeros, lo que eleva el precio al que el país recibe las entradas de capital. Tanto los factores internos como externos contribuyen a que las tasas de interés locales se sitúen muy por encima de las internacionales. Esos costos de capital, a su vez, afectan la capacidad de competencia internacional de la producción nacional, con el debilitamiento consiguiente del balance de pagos. Esto, por su parte, se retroalimenta al sistema en términos de un menor nivel de actividad, mayor informalización y debilitamiento adicional de las empresas formales y sus bancos.

En este punto, el sistema de precios se ve afectado por factores distributivos en sus principales mercados:

i) El mercado de divisas se ha segmentado por un sistema de tipos de cambio múltiples defacto, constituido por un tipo financiero único y un gran número de tipos para productos o bienes primarios debido a la existencia de una estructura diversificada de aranceles e impuestos al comercio;

ii) El mercado del trabajo se ve afectado gravemente por la diferencia de remuneración media en el sector de competencia monopolística y el costo marginal del trabajo, en general, así como por legislación laboral cada vez menos operante, pero que subsiste

iii) El mercado de capitales se divide profundamente por la exigencia de garantías para la extensión del crédito y la debilidad de su propagación al sector informal.

Con interdependencia de los mercados, en equilibrio general, está claro que ningún precio de mercado es igual a su respectivo precio sombra. La asignación por mercado en este caso no será eficiente en términos de Pareto. Sin embargo, tampoco hay ninguna garantía de que la distribución será satisfactoria, a pesar de que el mercado de trabajo actúe como una red de seguridad del mercado.

\section{IV}

\section{La fase del ajuste estructural}

La política de ajuste estructural es un conjunto básico de medidas que pretenden corregir las distorsiones existentes; contiene los elementos siguientes:

i) liberalización del comercio (comercio "casi libre"), v.g. bajos aranceles, sin subsidios a la exportación:

\footnotetext{
6 En Otero, 1996, Sec. 5 puede encontrarse una descripción esclarecedora respecto de las diferentes fases de desarrollo de! sislema financiero y su interacción con los acontecimientos de la economía real.

7 Véanse Ramos (1980) y Mezzera (1981)
}

ii) tipo de cambio de libre flotación, "de equilibrio";

iii) tasas de interés de mercado;

iv) escasa, o ninguna, intervención del gobierno en los mercados;

v) equilibrio fiscal;

vi) privatización;

vii) flexibilización del mercado de trabajo.

Para nuestros propósitos, los elementos más críticos de este conjunto de políticas están en el ámbito de la política de comercio exterior. Un comercio "casi libre" con un tipo de cambio flexible, se traduce de hecho en bajos aranceles con tipo de cambio elevado. 
En este sentido, es casi lo mismo que la solución de devaluación general no adoptada por los países de América Latina en las primeras etapas de su fase de industrialización activa. Surgen entonces las siguientes preguntas: Si esa política de bajos aranceles y elevado tipo de cambio no se llevó a cabo por ser inaceptable desde el punto de vista de la distribución, ¿qué ha pasado en estos años que la hacen factible ahora?

La respuesta comprende dos tipos de efectos: i) evolución diferente de las productividades de los sectores $\mathrm{y}$, ii) cambios en la estructura de propiedad de los recursos.

La productividad en los diferentes sectores en América Latina cambió a ritmos distintos como resultado de una variedad de factores interactuantes:

i) Aprendizaje por experiencia: las empresas se mueven hacia abajo en su curva de aprendizaje a medida que ganan experiencia. Como había que aprender más en las nuevas actividades industriales que en las primarias, más viejas, más establecidas, la productividad creció más en los sectores industriales que en los primarios ya establecidos;

ii) Penetración de mercados de exportación: Las empresas latinoamericanas han aprendido a comercializar sus exportaciones en una cantidad de sectores en los que originalmente no eran capaces de vender fuera del país. Esto implica un mayor precio FOB efectivo, y por lo tanto equivale a una mayor productividad por unidad de factor empleado.

iii) Los costos de transporte y comunicaciones han bajado, un factor independiente que, de todos modos, ha incrementado los precios FOB efectivos y reducido los precios CIF para una amplia variedad de productos. Además, como en el transporte marítimo se impuso el de contenedores sobre el de carga general, bajó el costo relativo del transporte de los productos básicos no primarios que no se acarrean a granel, lo que se tradujo, en fin de cuentas, en una mayor productividad de la producción industrial.

iv) La violencia y la insurrección afectaron a sectores rurales de muchos países, especialmente Perú, El Salvador, Nicaragua y partes de las regiones selváticas de Bolivia y Colombia. La violencia elevó el costo de producción de los sectores primarios, haciéndolos relativamente menos productivos que los sectores industriales urbanos.

v) En algunos países se introdujeron cultivos nuevos (algunos ilegales), como la coca y el kiwi, que contribuyeron a crear una actividad altamente rentable y productiva en el sector primario.

El efecto combinado de estos elementos fue de achatar la curva de oferta agregada disminuyendo las diferencias de productividad entre los diferentes sectores. Esto se señala en el gráfico 3, el que muestra también, para fines de comparación, la curva de la oferta de comienzos de la fase de industrialización activa.

Los cambios en la propiedad asumieron dos formas principales:

i) La reforma agraria: en muchos países de América Latina se hizo un esfuerzos sistemático para transferir tierras de los latifundios a los productores más pequeños y, en algunos casos, a cooperativas o asociaciones de productores. Más recientemente ha habido la tendencia a promover el funcionamiento activo de los mercados de tierra agrícola.

ii) La propiedad de la minería metálica y el petróleo fue transferida al Estado. Sus antiguos dueños eran en su mayoría extranjeros, aunque también grandes empresas nacionales. La nacionalización tuvo el efecto de transferir utilidades de una parte importante del sector primario al Estado, de forma equivalente a un impuesto del $100 \%$ sobre las utilidades de los productores primarios. En efecto, este régimen puso en práctica parte del sistema de recuperación de utilidades imprevistas que podría haberse logrado con la devaluación compensada a comienzos de la fase de industrialización activa, sistema que superaba la capacidad administrativa de la época.

Cuando estos dos cambios se analizan conjuntamente, se advierte que una política de comercio "casi libre" en las actuales circunstancias generaría un efecto distributivo menor que años atrás, y que esta redistribución beneficiaría a un grupo más amplio de propietarios agrícolas y principalmente al Estado, en el caso de la minería. En consecuencia, se han disipado en gran parte las objeciones por motivos distributivos contra una política de aranceles bajos y tipo de cambio elevado. Por ello, parecería que una política rechazada hace

GRÁFICO 3

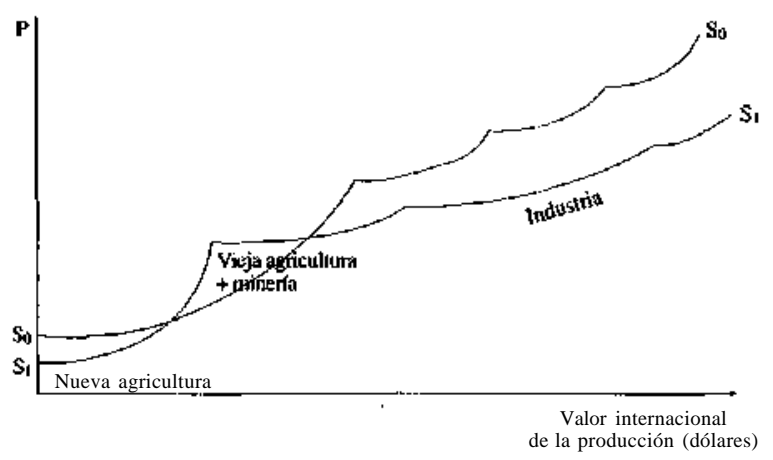


algunos años por sus consecuencias distributivas podría ser factible hoy.

La realidad del ajuste estructural, sin embargo, ha sido algo distinta que la predicción teórica. Más que aranceles bajos con tipo de cambio elevado, se han dado aranceles bajos con tipo de cambio bajo, como lo indica el gráfico 4. El tipo de cambio bajo ha sido consecuencia de la importante entrada de capitales que siguió a la gran reducción del riesgo percibido de invertir en América Latina, gracias al viraje de política que significó la adopción del ajuste estructural, así como a las atractivas oportunidades de inversión que se abrieron con los procesos de privatización de empresas públicas y el alto interés prevaleciente en el sector financiero.

Los tipos de cambio más bajos, junto con la liberalización de las tasas de interés y la flexibilización del mercado del trabajo, tuvieron muchas consecuencias:

i) El bajo tipo de cambio hizo que una variedad de productos locales quedaran fuera de la competencia. Esto se aprecia en el gráfico 4.

ii) Como corolario de lo anterior, un número creciente de personas fue empujado al sector informal. Hasta donde el sector fue capaz de responder absorbiendo a esta población creciente, a través de la informalización de una mayor cantidad de actividades, de la expansión geográfica, o mediante la reducción de las expectativas de costo de vida, se amplió la diferencia entre salarios de mercado y costo marginal del trabajo. ${ }^{8}$ En algunos casos (como Argentina), el sector informal no pudo absorber el influjo y resultaron altas tasas de desempleo abierto.

iii) La presión de la competencia externa sobre la empresa formal por la rebaja de aranceles, y el alza de las tasas de interés producto de la liberalización de los mercados de capital repercutió negativamente sobre las finanzas de las empresas formales, lo que debilitó la calidad de los activos mantenidos por el sistema bancario e incrementó su cartera de préstamos incobrables. Otra consecuencia fue reducir la capacidad del sistema bancario para innovar con vistas a llegar al segmento dinámico del sector informal con los instrumentos de depósito y crédito apropiados.

iv) La crisis en los sistemas bancarios llevó al cierre de instituciones financieras $\mathrm{y}$, en algunos casos, a pérdidas para los depositantes.

\footnotetext{
${ }^{8}$ Nótese, sin embargo, que la reducción del ingreso esperado reduce el cuociente entre ingreso de mercado y precio sombra del trabajo.
}

GRÁFICO $A$

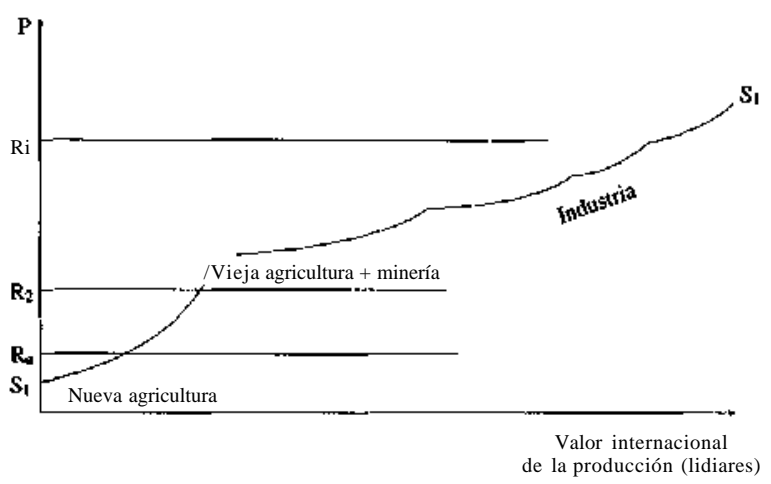

v) Compañías formales debilitadas fueron vendidas a inversionistas extranjeros o declararon la quiebra, dejando hueco para ser reemplazadas por nuevas empresas de propiedad extranjera.

vi) La flexibilización del mercado de trabajo tuvo escaso impacto ya que el sector formal estaba atravesando por un proceso de contracción significativa, y la mayor parte de la acción se concentró en el mercado informal, donde no regía la legislación laboral o no se aplicaba en forma rigurosa.

En forma paralela, los programas de privatización establecieron una dinámica propia. Las grandes privatizaciones fueron principalmente de servicios públicos, que, por su tamaño, sólo podían adquirirlas inversionistas extranjeros o consorcios con importante participación foránea. Estos inversionistas, sin embargo, tenían buen conocimiento de la experiencia pasada en que los gobiernos regulaban sus precios y restringían sus utilidades. Por ello, en esta ronda de privatizaciones, los inversionistas se aseguraron de obtener una adecuada protección para sus ventas, contra la inflación local, la devaluación y el control cambiario. En esencia, obtuvieron la indización cambiaría de sus utilidades. Esto generó un vínculo directo entre el nivel de actividad y la rentabilidad en el sector de bienes no transables y la repatriación de utilidades en el balance de pagos. Un fenómeno similar ocurrió en el sector privado de bienes no transables, donde la inversión privada externa aumentó significativamente su participación en actividades como el comercio minorista (supermercados, en especial). Aquí también, el nivel de actividad y la rentabilidad derivada se conectaron directamente con la corriente de remesas del balance de pagos. 
La entrada de inversión privada extranjera tuvo tres efectos importantes:

i) Un tipo de cambio sobrevaluado con relación al equilibrio de largo plazo en un régimen de aranceles bajos;

ii) Una nueva distribución de la propiedad, que bien puede ser presagio de futuras pugnas distributivas;

iii) Una dinámica por la cual la expansión económica interna lleva a una mayor rentabilidad del sector de bienes no transables, lo que a su vez induce un mayor egreso de divisas en la cuenta de remesas, lo que limita por su lado la expansión por el lado del balance de pagos. Esta se convierte en una nueva modalidad de la antigua limitación cambiaría para el crecimiento de América Latina.

En esta etapa de la fase de ajuste estructural, los viejos problemas distributivos están obrando entre sí con las expectativas generadas por la propia política de ajuste estructural para producir un nuevo conjunto de problemas de asignación: la entrada de capital ha generado un tipo de cambio que no corresponde al de equilibrio de largo plazo del balance de pagos, ni refleja exactamente el costo marginal social o el beneficio marginal social de la divisa en el presente. En el mercado del trabajo, el mercado informal sigue interponiéndose entre los salarios de mercado y el costo marginal del trabajo, mientras que en el mercado de capitales, la combinación de requerimientos de garan-

\section{V}

\section{Resumen}

La exigencia de crear más puestos de trabajo hizo necesaria la industrialización. Para lograr la industrialización hubo que cubrir un diferencial de productividades. Para ello, había dos opciones factibles: a) preservar la eficiencia de asignación generando una redistribución fuertemente regresiva; y b) perder eficiencia en la asignación pero mantener los grandes rasgos de la distribución. Los gobiernos escogieron ésta última con lo cual introdujeron distorsiones permanentes en el mercado cambiario.

La industrialización sustitutiva de importaciones llegó a un punto muerto de estancamiento. La creciente presión en el mercado de trabajo pudo haber llevado a una fuerte caída de los salarios. En cambio, surgió el mercado informal, el que, gracias a su estructura com- tías y la debilidad acumulada de las empresas del sector formal hace que las tasas de interés no reflejen adecuadamente la productividad social marginal de la inversión ni el costo social marginal del ahorro. Ningún precio de mercado refleja el verdadero equilibrio de su mercado. Menos todavía reflejan los precios de mercado el equilibrio subyacente de los precios sombra.

Más aún, los sesgos de asignación operan en una dirección calculada para retardar la convergencia hacia un sistema de precios más eficiente. Como el tipo de cambio está sobrevaluado y el costo de mercado del trabajo sobredimensiona su verdadera escasez, la economía va a tender a subproducir y a sobreutilizar divisas en tanto que a subutilizar mano de obra. Así, la secular escasez de divisas se va a superar a una velocidad subóptima, en tanto que el exceso de dotación de mano de obra se absorberá más lentamente que el óptimo.

En esta etapa el papel que desempeñan las tensiones en las distorsiones del sistema de precios reside, por una parte, en el mercado de trabajo, a juzgar por la existencia y tamaño del sector informal y, por otra, en la línea de quiebre, apenas visible hasta ahora, entre los factores internos de la producción (tanto capital como trabajo) y los inversionistas extranjeros, particularmente en el sector de bienes no transables de la economía. petitiva monopolística segmentó los mercados de bienes y aseguró una distribución mínima aceptable.

No hubo políticas públicas al respecto. Una exigencia distributiva llevó al mercado a desarrollar una red de protección "natural". Sin embargo, nuevamente se sacrificó la eficiencia en la asignación y se introdujo una distorsión permanente en el mercado de trabajo,

El desarrollo financiero no pudo satisfacer las nuevas necesidades y la segmentación del mercado de capitales reforzó más aún las distorsiones del sistema de precios.

Gracias a la liberalización, la política de ajuste estructural removió algunas de las distorsiones de precios en el mercado de divisas. Sin embargo, estimuló así una entrada de capitales externos que generó una 
sobrevaluación considerable. Al mismo tiempo, sigue la división en el mercado del trabajo, quizás más fuerte que nunca. La liberalización del comercio exterior ha aparecido en la contabilidad de los bancos como debilitamiento de las garantías y aumento de las deudas incobrables de empresas que ya no gozan de protección por la rebaja de los aranceles y con un tipo de cambio sobrevaluado.
De esta forma, el sistema de precios de mercado no da, ni de lejos, las señales correctas para una buena asignación de los recursos. Al propio tiempo, la necesidad de ingresos sigue estimulando el crecimiento del sector informal, mientras que el capital y el trabajo miran con desconfianza la inversión extranjera, sin saber si es amiga o enemiga.

(Traducido del inglés)

\section{Bibliografía}

Balassa, B. y otros (1982): Development Strategies in Semi-Industríal Economics. Baltimore, Pennsylvania, Johns Hopkins University Press.

CARTTA (Cámara Argentina de Radio, Televisión, Telecomunicaciones y Afines) (1966): Proyecto de modificación de la estructura arancelario-cambiaria, Buenos Aires, septiembre, mimeo.

Chamberlain E. (1933): The Theory of Manopolistic Competition, Cambridge, Massachusetts, Harvard University Press.

Diamand, M. (1973): Doctrinas económicas, desarrollo en independencia, Buenos Aires, Editorial Paidós.

Mezzera, i. (1981): Segmented labour markets without policyinduced labour market distortions, World Development, vol. 9 , $\mathrm{N}^{\circ}$ 12, Oxford, Pergamon Press.
Otero, C. (1996): Propuesta para el financiamiento de las pequeñas y microempresas a través del mercado de capitales, Lima, Bolsa de Valores de Lima, mimeo.

Ramos, J. (1980): Capital Market Segmentation, Underemployment and íncome Distribution, Monograph, $\mathrm{N}^{\circ} 16$, Ginebra, Organización Internacional del Trabajo (OIT), Programa Regional del Empleo para América Latina y el Caribe (PREALC), septiembre.

Schydlowsky, D. M, (1967): From import substitution to export promotion for semi-grown up industries: A policy proposal, The Journal of Development Studies, Londres, Frank Cass, julio,

(1972): Latin American trade policies in the 1970s, The Quarterly Journal of Economics, vol. 86, $\mathrm{N}^{\circ} 2$, Londres, Oxford University Press. 